\title{
Carbon Dioxide Gas as a Venous Contrast Agent to Guide Upper-Arm Insertion of Central Venous Catheters
}

\author{
Seong T. Hahn, ${ }^{1,2}$ Thomas Pfammatter, ${ }^{1}$ Kyung J. Cho ${ }^{1}$ \\ ${ }^{1}$ Department of Radiology, University of Michigan Hospitals, 1500 E. Medical Center Dr., Ann Arbor, MI 0030/48109, USA \\ ${ }^{2}$ Department of Radiology. St. Mary's Hospital, Catholic University Medical College, Catholic Medical Center, \#62 Youido-dong, \\ Yongdungpo-gu, Seoul 150-010, Korea
}

\begin{abstract}
Purpose: Evaluate in a prospective randomized study carbon dioxide $\left(\mathrm{CO}_{2}\right)$ gas compared to iodinated contrast agent for image-guided placement of peripherally inserted central venous catheters (PICCs).

Methods: The upper-arm approach to the central vein was used for placement of PICCs in 74 patients requiring intermediate or long-term central venous access. Fluoroscopy was used to obtain venous access during peripheral injection of $\mathrm{CO}_{2}(\mathrm{n}=41)$ or low osmolar contrast material (Omnipaque $240 \mathrm{mgI} / \mathrm{ml})(\mathrm{n}=33)$.

Results: Placement of PICCs was accomplished in $88 \%$ of the $\mathrm{CO}_{2}$ group and in $100 \%$ of the contrast group, with a mean venipuncture of two in both groups. Venous access was unsuccessful in five patients with $\mathrm{CO}_{2}$ due to a small vein, venous spasm, or technical failure. The mean and range of procedure times were $22.8 \mathrm{~min}(13-64 \mathrm{~min}$ ) with $\mathrm{CO}_{2}$ and $23.2 \mathrm{~min}(12-60 \mathrm{~min})$ with contrast material. The average and range of $\mathrm{CO}_{2}$ and nonionic contrast volumes injected during the procedure were $35.4 \mathrm{ml}$ $(5-300 \mathrm{ml})$ and $27.8 \mathrm{ml}(8-120 \mathrm{ml})$, respectively. Vital signs and oxygen saturation did not change significantly during or after injection of $\mathrm{CO}_{2}$. There was no incidence of adverse reaction following $\mathrm{CO}_{2}$ injection.

Conclusion: $\mathrm{CO}_{2}$ gas is a useful contrast agent to guide upper-arm insertion of PICCs and may be a safe alternative in patients with renal insufficiency and/or allergy to iodinated contrast material.
\end{abstract}

Key words: $\mathrm{CO}_{2}$ gas - Arm venography - Central venous access-Contrast allergy

Placement of a catheter into the superior vena cava or right atrium allows for long-term treatment with anti-

Correspondence to: K.J. Cho, M.D. biotics, chemotherapeutic agents, nutrition, and hemodialysis [1-3]. The catheter may be placed percutaneously through the subclavian, internal jugular, or upper arm veins. Recently, the upper-arm venous access has been used for insertion of peripherally inserted central venous catheters (PICCs) with increasing frequency $[1,2,4]$. The procedure involves puncture of a basilic or brachial vein in the middle one-third of the upper arm under fluoroscopic guidance during more peripheral injection of iodinated contrast material. Another method of guiding venipuncture that is useful in patients with renal failure or hypersensitivy to contrast material is ultrasound-guided venipuncture [1]. We have used carbon dioxide $\left(\mathrm{CO}_{2}\right)$ gas as an alternative contrast agent to aid upper-arm placement of PICCs. The purpose of this study was to determine the safety and efficacy of $\mathrm{CO}_{2}$ as a contrast agent for visualization of the upper arm veins to guide venipuncture for placement of PICCs.

\section{Materials and Methods}

The upper-arm venous approach for insertion of PICCs was used in 74 patients, 30 men and 44 women, from February 1, 1994 to June 30,1994 . The patients' ages ranged from 13 to 86 years (mean 51 years). Indications for central venous access included long-term treatment with antibiotics $(n=37)$, total parenteral nutrition $(n=11)$, chemotherapy $(n=13)$, long-term intravenous hydration $(n=2)$, pain control $(n=1)$, and others $(n=10)$. Because the safety of intravenous $\mathrm{CO}_{2}$ injection was unknown, the patients with pulmonary insufficiency, asthma, and diabetes were excluded from the study. The study patients were randomized into two groups. Group 1 (male/ female $=17 / 24$, mean age $=51$ years) received $\mathrm{CO}_{2}$ through a more peripheral venous access to visualize the target vein to guide venipuncture. In Group 2 (male/female $=13 / 20$, mean age $=51$ years), low osmolar contrast material (Omnipaque $240 \mathrm{mg} \mathrm{V} / \mathrm{ml}$ ) was used to visualize the target vein. Success rate, number of venipunctures made to obtain venous access, total procedure time, volume of $\mathrm{CO}_{2}$, and contrast material used were recorded. After completion of the 


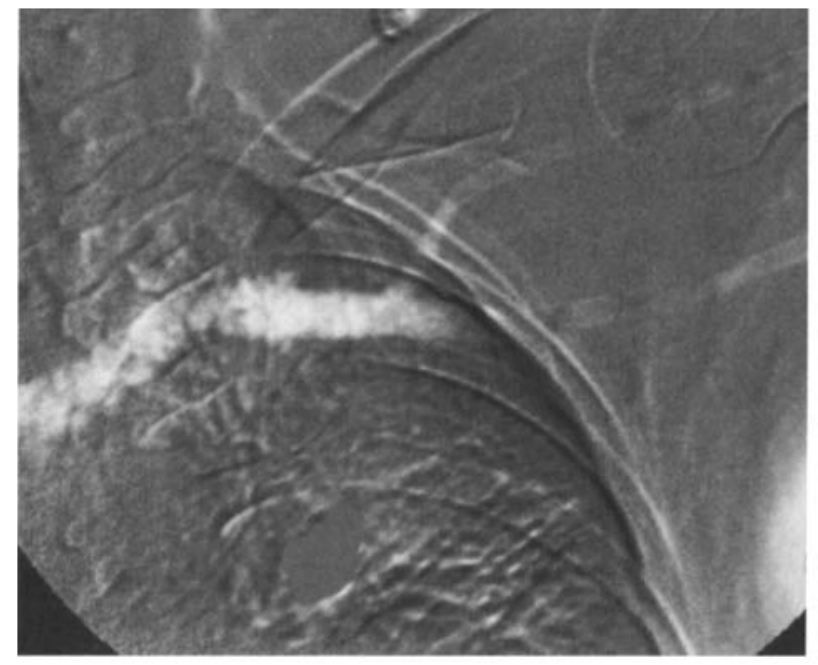

Fig. I. $\mathrm{CO}_{2}$ /DSA of upper arm veins showing patent subclavian and innominate veins.

procedure, the patients were questioned about any discomfort or pain during the injection of $\mathrm{CO}_{2}$.

Fluoroscopic imaging quality of target vein visualization with $\mathrm{CO}_{2}$ was assessed by one author $(\mathrm{STH})$, as was image quality of $\mathrm{CO}_{2}$ digital subtraction venograms (KJC). In this study, acute renal function impairment was defined as an increase in serum creatinine by $50 \%$ and/or $1 \mathrm{mg} / \mathrm{dl}$ within $48 \mathrm{~h}$ after the procedure, resulting in a creatinine level above the normal range.

\section{Technique}

The technique for placement of PICCs was described previously [4]. A modification of the previously described technique was performed using a 21-gauge micropuncture kit (Cook Inc., Bloomington, IN, USA) to access the vein. In all patients, $20-40-\mathrm{ml}$ boluses of $\mathrm{CO}_{2}$ or $20-30-\mathrm{ml}$ boluses of iodinated contrast material were injected through a peripheral venous access, to document patency of the subclavian and innominate veins using digital subtraction angiography (DSA) (Fig. 1). The largest vein, usually basilic or brachial, was punctured under fluoroscopic guidance during injection of contrast agent (Fig. 2). Roadmapping technique was not used for venipuncture. No tourniquet was applied around the upper arm during the venipuncture with $\mathrm{CO}_{2}$. When spasm developed following the venipuncture, $50-100 \mu \mathrm{g}$ of nitroglycerine was injected into the peripheral vein. After placement, the PICC was flushed with $10 \mathrm{ml}$ of normal saline containing 1000 units of heparin, and covered with an occlusive dressing. PICC placement was then confirmed by a chest radiograph (Fig. 2). The PICCs used for this study were 5 Fr single lumen (Cook) or 4.5 Fr double lumen (HDC Corporation, San Jose, CA, USA) catheters.

Medical grade $\mathrm{CO}_{2}$ gas (Airco Cylinder Corp., Ann Arbor, MI, USA) was used for the procedure. A hand-held syringe, connected to a specially designed closed system, was employed for a safe, reliable delivery of carbon dioxide. The system included a manifold (Morse Manifold, NAMIC, Medical Production Division, Glens Fall, NY, USA) for delivery of $\mathrm{CO}_{2}$ and vent, and a three-way high pressure stopcock (Sorenson Intralock, Abbott Critical Care System, Abbott Laboratories/Hospital Products Div., North Chicago, IL, USA) for infusion of heparinized normal saline. In order to minimize discomfort due to explosive delivery of the gas, the fluid in the delivery system was displaced by injecting $5-10 \mathrm{ml}$ of the gas before $\mathrm{CO}_{2}$ / DSA of the subclavian vein. Vital signs, including pulse rate, respiratory rate, oxygen saturation, blood pressure, and EKG, were mon-
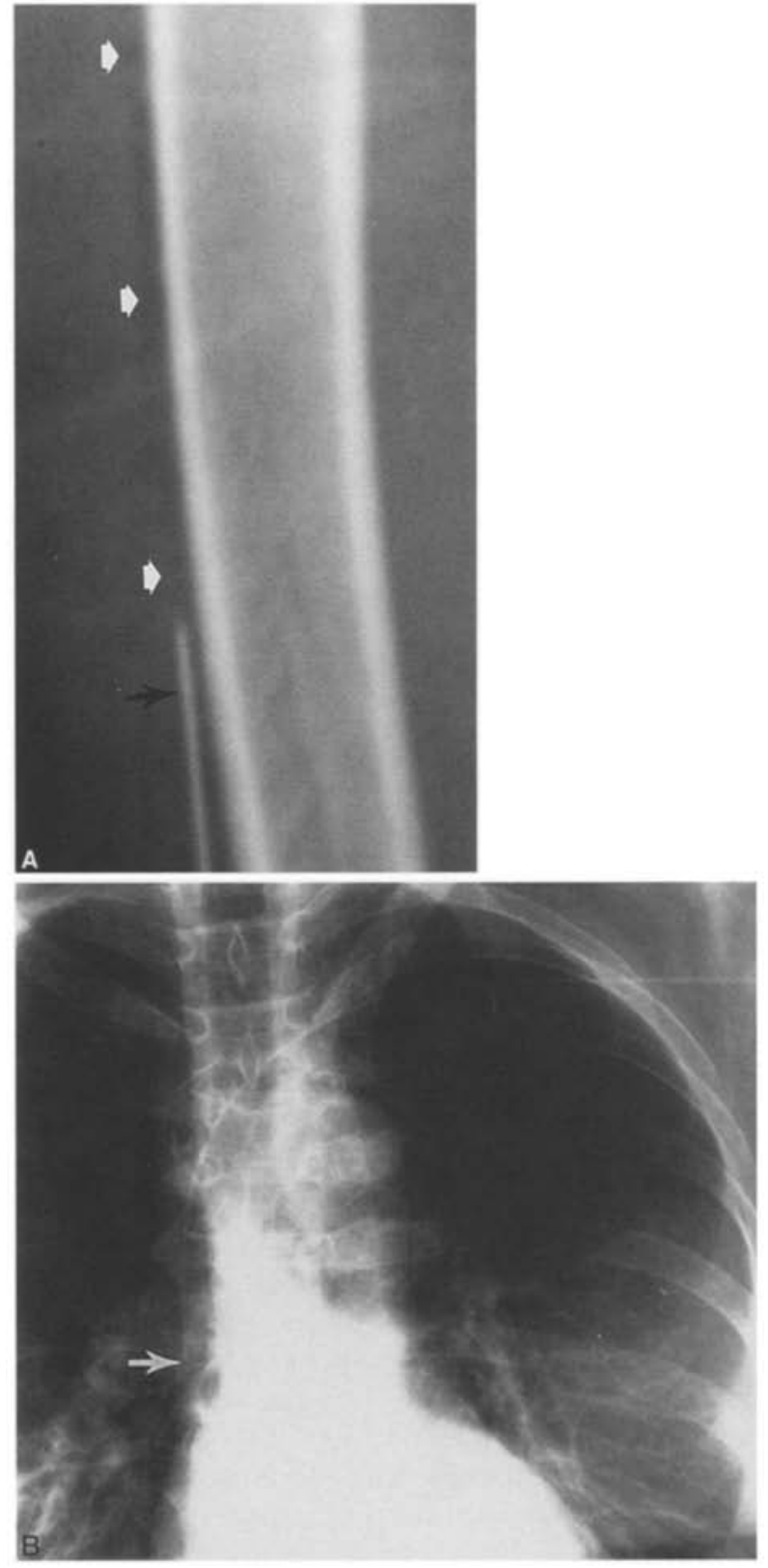

Fig. 2. Radiograph taken during PICC insertion. A A 21 gauge needle (arrow) is inserted into the brachial vein filled with $\mathrm{CO}_{2}$ (arrowheads). The target vein is poorly seen due to the poor resolution of the $105-\mathrm{mm}$ photocamera picture. The gas in the vein was better seen under fluoroscopy. B Postplacement radiograph confirms optimal placement with catheter tip at the junction of superior vena cava and right atrium (arrow).

itored during the procedure. Pre-and postprocedure serum creatinine levels were recorded.

\section{Results}

PICCs placement was accomplished in $36 / 41$ patients using $\mathrm{CO}_{2}$ gas and in $33 / 33$ patients using contrast ma- 
terial. In the five patients who had failed venipuncture with $\mathrm{CO}_{2}$, venous access was obtained subsequently with contrast medium. The mean number of venous punctures required to obtain venous access was comparable between the two groups, with a mean puncture of two in both groups. The number of punctures in the patients with successful PICCs placement ranged from 1 to 9 in Group 1 and from 1 to 8 in Group 2. The mean procedure time was $22.8 \mathrm{~min}$ (range 13-64 min) in Group 1 and 23.2 min (range 12-60 min) in Group 2. The mean volume of $\mathrm{CO}_{2}$ and contrast material injected was $35.4 \mathrm{ml}$ (range, 5-300 ml) in Group 1 and $27.8 \mathrm{ml}$ (range, $8-120 \mathrm{ml}$ ) in Group 2. The results are summarized in Tables 1 and 2.

Vital signs and oxygen saturation did not change during and after the injection of $\mathrm{CO}_{2}$. No patient developed complications or renal failure following the placement of PICCs under $\mathrm{CO}_{2}$ guidance. The mean and range of pre- and postprocedure serum creatinine levels in both groups are summarized in Table 3. Two patients in Group 2 developed transient elevation of creatinine lasting a few days. In the first patient, serum creatinine levels increased from $1.0 \mathrm{mg} / \mathrm{dl}$ before the procedure to $1.5 \mathrm{mg} / \mathrm{dl}$ after the procedure. In the second patient, serum creatinine increased $0.8 \mathrm{mg} / \mathrm{dl}$ to a postprocedure creatinine of $1.6 \mathrm{mg} / \mathrm{dl}$.

Fluoroscopic images of the target veins filled with $\mathrm{CO}_{2}$ were rated as excellent (complete filling of target veins of normal caliber) in $39 \%$, good (incomplete filling of target veins of normal caliber) in $49 \%$, and poor (incomplete filling of target veins of small caliber) in $12 \%$. The quality of the $\mathrm{CO}_{2} / \mathrm{DSA}$ images of the subclavian veins was rated as excellent (complete image of the subclavian vein) in 54\%, good (adequate image of the subclavian vein, but with incomplete filling of the venous lumen) in $37 \%$, and poor (inadequate image of the subclavian vein with incomplete filling of the venous lumen) in $9 \%$. The $\mathrm{CO}_{2} / \mathrm{DSA}$ images documented patency of the subclavian and innominate veins in all patients studied. The five failures in the $\mathrm{CO}_{2}$ group could be attributed to the small veins $(n=3)$, venous $\operatorname{spasm}(n=1)$, and technical failure $(n=1)$. Four patients complained of mild pain and discomfort at the injection site when a $20-30-\mathrm{ml} \mathrm{CO}_{2}$ bolus was injected for visualization of the subclavian veins.

\section{Discussion}

The upper arm approach for placement of PICCs for long-term venous access has been used with increasing frequency at this institution. The central location of the catheter tip provides extended central venous access for administration of hyperalimentation, chemotherapy, or antibiotic therapy. Because of higher success rate and lower complications when inserted under fluoroscopic
Table 1. Summary of the clinical findings and results of PICCs placement

\begin{tabular}{lll}
\hline & $\begin{array}{l}\text { Group I } \\
\left(\mathrm{CO}_{2}\right) \\
(\mathrm{n}=41)\end{array}$ & $\begin{array}{l}\text { Group 2 } \\
(\mathrm{ICM}) \\
(\mathrm{n}=33)\end{array}$ \\
\hline $\begin{array}{l}\text { Mean age (yrs) } \\
\text { Sex distribution (M/F) }\end{array}$ & $\begin{array}{l}51(13-86) \\
\text { Puncture success }\end{array}$ & $\begin{array}{l}51(23-79) \\
13 / 20\end{array}$ \\
$\begin{array}{l}\text { Mean number of punctures to access } \\
\text { Mean procedure time (min) }\end{array}$ & $2(1-9)$ & $100 \%$ \\
Mean volume for puncture (ml) & $22.8(13-64)$ & $23.2(12-60)$ \\
\hline
\end{tabular}

ICM = iodinated contrast medium; $($ ) = range

Table 2. Number of venipunctures in two groups with successful PICC placement (mean $=2$ in both groups)

\begin{tabular}{lll}
\hline $\begin{array}{l}\text { Number of } \\
\text { punctures }\end{array}$ & $\begin{array}{l}\text { Group 1 }\left(\mathrm{CO}_{2}\right) \\
\text { Number cases }(\%)\end{array}$ & $\begin{array}{l}\text { Group 2 (ICM) } \\
\text { Number cases (\%) }\end{array}$ \\
\hline 1 & $24(67)$ & $19(58)$ \\
2 & $5(14)$ & $5(15)$ \\
3 & $3(8)$ & $4(12)$ \\
$4-9$ & $4(10)$ & $5(15)$ \\
\hline
\end{tabular}

ICM $=$ iodinated contrast medium

Table 3. Serum creatinine levels before and after PICC placement

\begin{tabular}{lll}
\hline & $\begin{array}{l}\text { Preprocedure mean } \\
\text { serum creatinine } \\
\text { (range) mg/dl }\end{array}$ & $\begin{array}{l}\text { Postprocedure mean } \\
\text { serum creatinine } \\
\text { (range) mg/dl }\end{array}$ \\
\hline Group 1 $\left(\mathrm{CO}_{2}\right)$ & $1.1(0.4-5.5)$ & $1.1(0.4-3.5)$ \\
Group 2 $(\mathrm{ICM})$ & $1.2(0.1-6.7)$ & $1.2(0.2-6.0)$ \\
\hline
\end{tabular}

ICM $=$ iodinated contrast medium

guidance, the PICCs are inserted by interventional radiologists, usually after an unsuccessful placement attempt by our intravenous nurse team. Our first step is the puncture of an upper arm vein under fluoroscopic guidance after injection of iodinated contrast material into a more peripheral vein. The clinical utility, high success rate, and lower complications have been documented $[1,2,4]$. With the use of iodinated contrast material, there are risks in patients with renal insufficiency and/or a history of allergy to contrast material. Two of our patients in group 2 with iodinated contrast had transient increase in serum creatinine levels lasting a few days. This is similar to the reported incidence of renal function impairment following angiographic studies [5].

Because of its lack of known renal toxicity and hypersensitivity reactions, $\mathrm{CO}_{2}$ is an attractive alternative to iodinated contrast material. Since Hawkins [6] described the use of $\mathrm{CO}_{2}$ as arterial contrast agent in 1982, the gas has been used as contrast medium for DSA in multiple organs $[6,7]$. Clinical and experimental stud- 
ies revealed that relatively large amounts of $\mathrm{CO}_{2}$ can enter the right heart and pulmonary circulation without producing a clinically significant pulmonary gas embolism [8-10]. $\mathrm{CO}_{2}$ has been used for the diagnosis of pericardial disease with an antecubital injection of 50 or $60 \mathrm{ml}$ of the gas over a 2-3-sec interval [10]. A canine study [11] revealed that a right atrial bolus of $\mathrm{CO}_{2}$ usually disappeared within $15-30$ seconds after injection. It was also demonstrated that intravenous injections of $\mathrm{CO}_{2}$ at a rate of $100 \mathrm{ml} / \mathrm{min}$ for a total volume of $10,000 \mathrm{ml}$ caused no demonstrable adverse effects in dogs. The volumes of $\mathrm{CO}_{2}$ injected per second in our patients were much smaller than those used for the diagnosis of pericardial effusion with intracardiac $\mathrm{CO}_{2}$. Because $\mathrm{CO}_{2}$ is 20 times more soluble in blood than oxygen or air [9], the gas is rapidly dissolved in blood and exhaled through the lungs. When $\mathrm{CO}_{2}$ is used as contrast agent, pre-procedure preparation with hydration is not necessary because it is not hyperosmolar. The low viscosity of $\mathrm{CO}_{2}$ allows injections of large amounts through a small catheter or needle.

The results of our study have demonstrated that $\mathrm{CO}_{2}$ gas is a safe and useful alternative contrast agent for upper-arm venography and placement of PICCs. The gas was well tolerated when injected into a peripheral vein in amounts of up to $300 \mathrm{ml}$. Visualization of the veins with $\mathrm{CO}_{2}$ was sufficient to guide puncture of the target vein under fluoroscopy in $86 \%$ of patients attempted. Patency of the subclavian and innominate veins could be easily documented with injections of $20-30 \mathrm{ml}$ of $\mathrm{CO}_{2}$ into a peripheral vein prior to insertion of PICCs. Even in the patients with slow venous flow, $\mathrm{CO}_{2}$ produced excellent digital subtraction imaging of the subclavian and innominate veins.

The angiographic appearance of $\mathrm{CO}_{2}$ is different from that of iodinated contrast material. When injected into a peripheral vein, $\mathrm{CO}_{2}$ tends to break and form gas bubbles. Their appearances vary with the amount of gas injected and the size of the vessels. As it flows through the vessel, $\mathrm{CO}_{2}$ displaces blood from the vessel lumen and reaches the upper arm veins within $5 \mathrm{sec}$ after hand injection into a peripheral vein. It should be noted that blood may not return when the needle is aspirated immediately after puncture because of the residual gas in the vein. Therefore, needle aspiration should be slightly delayed to allow refilling of the veins with blood.

When multiple upper-arm punctures were made during a central venous access procedure, we experienced extravasation of iodinated contrast material from the puncture holes. This usually obscured the target vein, making subsequent punctures difficult. Extravasation was not a problem with $\mathrm{CO}_{2}$ as the gas passed through the puncture sites. However, as venous punc- ture was frequently accompanied by spasm, diversion of gas flow through adjacent veins around the spasm site resided. Unless the spasm is relieved by intravenous nitroglyerine, repuncture should be made at other sites where the veins are filled with the gas.

Another physical property of $\mathrm{CO}_{2}$ that plays an important role in $\mathrm{CO}_{2} / \mathrm{DSA}$ is compressibility. $\mathrm{CO}_{2}$ delivery by a standard power injector or manual injection would initially compress the gas and result in delivery of the majority of $\mathrm{CO}_{2}$ in an explosive manner. This form of $\mathrm{CO}_{2}$ delivery may result in unsatisfactory filling of the arterial system. In the venous system, the explosive delivery of $\mathrm{CO}_{2}$ may cause pain and discomfort at the delivery site. To diminish such explosive delivery of $\mathrm{CO}_{2}$, a specially designed injection system and technique are necessary. To clear the fluid and blood in the catheter that cause gas compression, 5-10 $\mathrm{ml}$ of $\mathrm{CO}_{2}$ should be injected over 5-10 sec before bolus injection of the gas.

$\mathrm{CO}_{2}$ is a useful venous contrast agent for upper extremity venography and allows visualization of the target vein for insertion of PICCs. It is a viable alternative in patients with renal insufficiency and hypersensitivity reactions to iodinated contrast material.

\section{References}

1. Hovsepian DM, Bonn J, Eschelman DJ (1993) Techniques for peripheral insertion of central venous catheters. J Vasc Intervent Radiol 4:795-803

2. Cardella JF, Fox PS, Lawler JB (1993) Interventional radiologic placement of peripherally inserted central catheters. J Vasc Intervent Radiol 4:653-660

3. Mauro MA, Jaques PF (1993) Radiologic placement of longterm central venous catheters: A review. J Vasc Intervent Radiol $4: 127-137$

4. Andrews JC, Marx MV, Williams DM, Sproat I, Walker-Andrews SC (1992) The upper arm approach for placement of peripherally inserted central catheters for protracted venous access. AJR 158:427-429

5. Gomes AS, Baker JD, Paredero VM, Dixon SM, Takiff H, Machleder HI, Moore WS (1985) Acute renal dysfunction after major arteriography. AJR 145:1249-1253

6. Hawkins IF (1982) Carbon dioxide digital subtraction arteriography. AJR 139:19-34

7. Weaver FA, Pentecost MJ, Yellin AE, Davis S, Finck E, Teitelbaum $G$ (1991) Clinical applications of carbon dioxide/digital subtraction arteriography. J Vase Surg 13:266-273

8. Moore RM, Braselton CR Jr (1940) Injections of air and carbon dioxide into a pulmonary vein. Ann Surg 112:212-218

9. Scatliff JH, Kummer AJ, Janzen AH (1959) The diagnosis of pericardial effusion with intracardiac carbon dioxide. Radiology 73:871-883

10. Turner AF, Meyers HI, Jacobson G, Lo W (1966) Carbon dioxide cineangiocardiography in the diagnosis of pericardial disease. AJR 97:342-349

11. Harvard BM, White RR, Walsh LLL JF (1959) Experimental studies in acute retroperitoneal carbon dioxide insufflation. J Urol 8:481-485 